\title{
UM NOVO OLHAR PARA AS DROGAS: AS PERSPECTIVAS E EFEITOS DA POLÍTICA DE REDUÇÃO DE DANOS PARA OS USUÁRIOS DE DROGAS NO CANADÁ
}

\section{GUILHERME ANTÔNIO RODRIGUES}

Graduando em Direito, modalidade integral - Escola Superior Dom Helder Câmara Belo Horizonte. E-mail: grodrigues101@gmail.com.

\section{CAIO AUGUSTO SOUZA LARA}

Mestre e Doutor em Direito pela Faculdade de Direito da Universidade Federal de Minas Gerais - UFMG. Professor da Escola Superior Dom Helder Câmara. Pesquisador Associado ao Programa RECAJ-UFMG - Acesso à Justiça e Solução de Conflitos. Secretário de Comunicação do Conselho Nacional de Pesquisa e Pósgraduação em Direito - CONPEDI. Belo Horizonte-MG. E-mail: caiolarabh@yahoo.com.br.

\section{RESUMO}

O tema-problema da pesquisa que se pretende desenvolver é o acesso a políticas de redução de danos para as drogas como fator de saúde pública aos usuários de drogas, em sua esfera biopsicossocial, e seus efeitos nas grandes cidades canadenses em curto e médio prazo. A crise de opioides hoje é uma emergência de saúde pública em toda América do Norte e hoje assola todas camadas sociais, sobretudo as que vivem em situação de vulnerabilidade. Em geral, essas drogas tais como a heroína, o fentanil, a oxicodona e por fim a hidrocodona, são injetáveis e dessa forma representam grandes riscos de transmissão de doenças como a hepatite $\mathrm{B}$ e $\mathrm{C}, \mathrm{HIV}$ e entre outras que se justificam por uma falta de higiene e vulnerabilidade quanto ao uso e descarte de seringas e outras formas de uso dessas 


\section{Personalidade Acadêmica Homenageada:}

Raymundo Juliano Feitosa (Universidade Federal do Rio Grande do Norte - UFRN)

drogas, além de falta de educação sexual e desconhecimento por boa parte da sociedade com relação as drogas e os cuidados necessários com esta. Em 2003, em Vancouver, surge o primeiro Centro de Injeção Supervisionado (SIF) da América do Norte tendo isenção da política de drogas canadense e jurisdição para funcionar conforme decidido pela Suprema Corte Canadense, como via de frear uma crise que assola boa parte do continente norte-americano, além de muitos países do Mundo. Dessa forma, segundo dados coletados pela pesquisa, foi analisado a mortalidade por pessoas em um raio de até 500 metros desses SIF em Vancouver, constatando que a taxa de mortalidade diminuiu cerca de $35 \%$ abaixando de 253.8 mortes, para 165,1 mortes por 100 mil pessoas. Além disso, nenhuma morte foi registrada nesse Insite. Com relação ao crime, foi realizada uma pesquisa em 2006 com dados criminais e foi constatado que não houve nenhuma significativa mudança nos 3 principais crimes nesta cidade. Com relação a diminuição do uso dessas drogas, o InSite foi associado a melhores taxas de início do tratamento da dependência, diminuição da injeção no próprio local e um aumento de mais de $30 \%$ no uso do serviço de desintoxicação. $O$ problema objeto da investigação científica proposta é: qual o custo-benefício da política de redução de danos com relação as drogas para a população canadense? A hipótese se baseia na política de redução de danos para as drogas analisando está no sentido de não eliminar o problema, mas sim de diminuir os impactos causados pela falta de políticas públicas, sendo o usuário visto como responsável pelos seus atos. O objetivo geral do trabalho é analisar os principais pontos destas políticas de redução de danos presentes nas grandes cidades canadenses, e seus efeitos e impactos na sociedade. A pesquisa que se propõe pertence à vertente metodológica jurídico-sociológica. No tocante ao tipo de investigação, foi escolhido, na classificação de Witker (1985) e Gustin (2010), o tipo jurídico-comparativo. O raciocínio desenvolvido na pesquisa será predominantemente dialético. De acordo com a técnica de análise de conteúdo, afirma-se que trata-se de uma pesquisa teórica, o que será possível a partir da análise de conteúdo dos demais dados colhidos na pesquisa. A partir do exposto, conclui-se preliminarmente que é preciso que novas formas e alternativas comecem a ser discutidas nos países mais afetados, tratando a droga e o usuário de forma mais humanizada. Isto seria capaz de reduzir os principais riscos 
Personalidade Acadêmica Homenageada:

Raymundo Juliano Feitosa (Universidade Federal do Rio Grande do Norte - UFRN)

e oferecer não somente o investimento em segurança, mas na educação de toda sociedade, na conscientização por parte dos usuários e dos indivíduos dos efeitos, no debate de toda sociedade livre de amarras preconceituosas, bem como fornecer um acesso mais digno as políticas públicas, lidando com o usuário de forma íntegra e respeitosa sem discriminações.

PALAVRAS-CHAVE: Redução de danos; descriminalização das drogas; Direitos Humanos; Canadá.

\section{REFERÊNCIAS}

BIDERMAN, lara. Conceito de redução de danos surgiu após a Primeira Guerra Mundial. Folha de São Paulo, 26 ago. 2018. Disponível em: https://www1.folha.uol.com.br/seminariosfolha/2017/08/1912980-conceito-dereducao-dedanos-surgiu-apos-a-primeira-guerra-mundial.shtml. Acesso em: 08 maio 2019.

BRAMHAM, Daphne. Drug addictions: A timeline of harm reduction measures. Vancouver Sun, 19 jul. 2018. Disponível em: https://vancouversun.com/news/national/drug-addictions-atimeline-of-harmreduction-measures. Acesso em: 10 maio 2019.

GODOY, Guilherme Augusto Souza. Toxicômano - Delinquente versus toxicodependente - Regulação das drogas como fenômeno destacado em desafios atuais do cenário global, ISSN: 2316-753X. Revista Jurídica - Unicuritiba, Curitiba. v. 2 2 $\quad$ n. $43 . \quad$ Disponível em: http://revista.unicuritiba.edu.br/index.php/RevJur/article/view/1900. Acesso em: 21 maio 2019.

GOVERNMENT OF CANADA. Canadian Drugs and Substance Strategy. Harm Reduction: Canadian Drugs and Substances Strategy. Disponível em: https://www.canada.ca/en/healthcanada/services/substance-use/canadian-drugssubstances-strategy/harm-reduction.html\#a2 Acesso em: 10 maio 2019

GUSTIN, Miracy Barbosa de Sousa; DIAS, Maria Tereza Fonseca. (Re)pensando a pesquisa jurídica: teoria e prática. 3a. ed. Belo Horizonte: Del Rey, 2010.

HART, Carl. Um preço muito alto. Rio de Janeiro: Zahar, 2014 
Personalidade Acadêmica Homenageada:

Raymundo Juliano Feitosa (Universidade Federal do Rio Grande do Norte - UFRN)

MARSHALL, B. D. L.; MILLOY M-J.; WOOD, Evan; MONTANER, J. S. G.; KERR, Thomas. Reduction in overdose mortality after the opening of North America's first medically supervised safer injecting facility: a retrospective population-based study. The Lancet, Elsevier, 23 abr. 2011. Disponível em: https://www.sciencedirect.com/science/article/pii/S0140673610623537. Acesso em: 10 abr 2019

MENDES, Oro. 14 anos após descriminalizar todas as drogas, é assim que Portugal está no momento. Awebic, 07 fev. 2018. Disponível em: https://awebic.com/democracia/comoportugal-descriminalizou-as-drogas-e-e-umexemplo-para-o-mundo/. Acesso em: 11 mai. 2019

O GLOBO. Overdose batem recorde com 72 mil mortes nos EUA. O Globo, 16 ago. 2018. Disponível em: http://www.oglobo.globo.com/sociedade/saude/overdosesbatem-recordecom-72-mil-mortes-nos-eua-22983160. Acesso em: 08 mai. 2019

SZÁBO, Ilona. 'As drogas já estão liberadas, mas sob o controle do crime'. [Entrevista concedida a] Litza Matos. O Tempo, Belo Horizonte, 27 jun. 2018. Disponível em: https://www.otempo.com.br/brasil/as-drogas-j\%C3\%A1-est\%C3\%A3o-liberadas-massob-ocontrole-do-crime-1.1862059. Acesso em: 11 mai. 2019

THE JOURNAL. FactCheck: Do supervised injection centres reduce drug-related crime?. The Journal.ie, 19 Feb. 2017. Disponível em: https://www.thejournal.ie/supervised-injectioncentres-crime-fact-check-3238499-

Feb2017/. Acesso em: 10 abr. 2019

WITKER, Jorge. Como elaborar uma tesis en derecho: pautas metodológicas y técnicas para el estudiante o investigador del derecho. Madrid: Civitas, 1985.

WOOD, Evan; TYNDALL, M. W.; ZHANG Ruth; MONTANER, J. S. G.; KERR, Thomas. Rate of detoxification service use and its impact among a cohort of supervised injecting facility users. PublMed.gov, 27 dec. 2006. Disponível em: http://www.communityinsite.ca/Wood_ADDICTION_TREATMENT.pdf. Acesso em: 10 abr. 2019

YOUNG, Leslie. More than 10,000 Canadians died from opioid overdoses in less than 3 years: PHAC. Global News, 10 abr. 2019. Disponível em: https://globalnews.ca/news/5151561/10000-canadian-opioid-deaths/. Acesso em: 08 mai. 2019 